\title{
CDISC SDTM Culture Medium Type Terminology
}

National Cancer Institute

\section{Source}

National Cancer Institute. CDISC SDTM Culture Medium Type Terminology. NCI

Thesaurus. Code C127264.

Terminology associated with the culture medium type codelist of the Clinical Data

Interchange Standards Consortium (CDISC) Study Data T abulation Model (SDT M). 